\title{
Development and Analysis of Sisal Fiber and Amla Powder Natural Hybrid Composite
}

\author{
Kshitij D. Moholkar, Sandeep. S. Wangikar, Shrikrushna B. Bhosale
}

\begin{abstract}
This paper aims on study of new types of natural hybrid composites. Many researchers are focusing on natural fiber composites but it is found that natural hybrid composites have better mechanical properties and better strength. The advantages like biodegradability, low cost of material, excess weight reduction, ecofriendly, renewable also helps to make them more noticeable. In this project fiber powder combinations of amla and sisal are used in which weight of fiber is kept same and powder percentage varied which gives more advantage than fiber-fiber hybrid composite due to smaller size of powder bonding strength increased and micro level bonding achieved.From these combinations of fiber and powder are manufactured by weight of amla powder $30 \%$ and micro analysis by considering different micron sizes 0-100,100-200,200-300 is made without disturbing weight of fiber and powder in two orientations Zero and Ninety degree.For $30 \%$ powder with ninety degree orientation gives best strength than others also in case of micro analysis 0-100 micron size with ninety degree and $30 \%$ powder gives the best results of strength.
\end{abstract}

Index Terms-Hybrid natural composite, Sisal-Amla, degree, scope, micron size, comparative analysis, Tensile Strength, Flexural Strength.

\section{INTRODUCTION}

Now a days car body parts including chassis in sport cars, cycles and bicycle parts are made using composites along with missiles, automobile and aircraft applications. Composites are used in a wide variety of applications, including aerospace, automotive parts, energy, marine, military,architecture, infrastructure, aeronautical, ship buildings, bath tubs, hot tubs, electrical boxes, circuit boards and sports applications like hockey sticks, golf clubs. The composites based on natural fiber reinforcement have generated wide scope for research and engineering in the last few decades because of their specific properties and application like small density, high specific strength, low cost, light weight, recyclability, biodegradability and environment friendly and have earned a special category of natural green composite [1-5]. The various advantages of hybrid composite such as biodegradability, renewable, low cost, eco-friendly and comparable high mechanical properties make them more noticeable and affordable in certain projects.

Problems associated with industrial and general applications are studied and modified area of hybrid natural composites is selected for better conclusions.

KshitijD. Moholkar, Sandeep. S. Wangikar, Shrikrushna B. Bhosale Department of Mechanical Engineering, SVERI's College of Engineering Pandharpur-413304
Tensile strengths, Flexural strengths and wear(\%) of all specimens are tested and reached at effective conclusion to get best composition and best results by studying different compositions and comparative analysis of it [6-18].

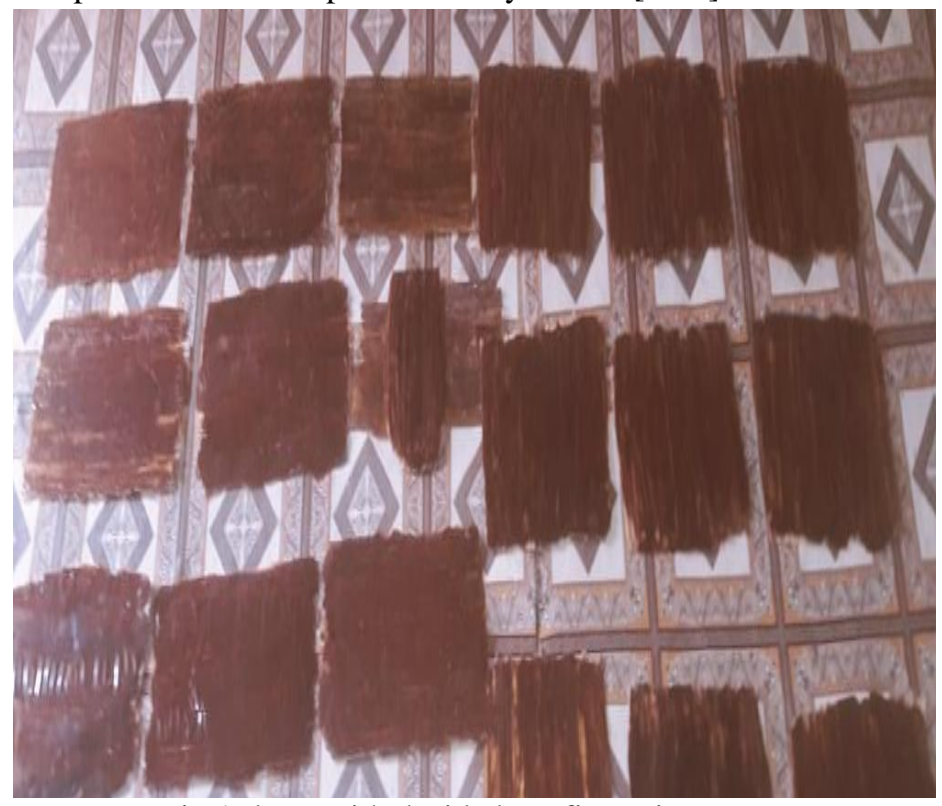

Fig.1Plates with decided configurations

\section{Methodology}

1.Drying of Powder-The drying of the powder is done for eight to ten hours in hot sun rays and it is found that the moisture present inside the powder is almost removed because the weight of the powder remains same. The weight reduction in powder is recorded and it is found that out of 1 $\mathrm{kg}$ Powder 8-10 gm weight is reduced.

2. Grain Size Testing and separation-At the start of project after drying of powder the grain size testing of the powder is performed by using Sieve Shaker's machine. The sensitivity of this is in microns. By performing experimentation it is found that average grain size of the Amla Powder lies between 105-125 microns. This powder is divided into 3 types-less than 100 microns, 100-200 microns and above 200 microns for preparation of specimens using different micron sizes.

3. Fiber Extraction-Fiber extration plays very importat role in selection of best fibers from available fibers.In this process sisal fibers of long length are collected separated and bundle of it is made.The fibers selected are good and with less defects. 
4. Chemical Treatment and Washing-There are several methods and chemicals from which chemical treatment can be done. Chemical treatment is required for straightening and increasing strength of fiber. It is observed from few literatures that chemical treatment plays important role in increasing flextural and other strengths of fiber by reducing lignin percentage of fiber. The chemicals which are most commonly used for chemical treatment are $\mathrm{NaOH}$, KCL, $\mathrm{CCl} 3$, Benzyl Peroxide, Hydrogen Peroxide etc. Out of these chemicals $\mathrm{NaOH}$ and hydrogen peroxide are used for chemical or sometimes called bleaching treatment. This treatment is done using $10 \%$ Hydrogen Peroxide.

5.Washing and Drying-Washing of fibers is also very important .After performing every chemical treatment all fibers are washed with distilled water for 2-3 times for removing sticky chemicals on fiber if remained after chemical treatment. Drying under sun is made for 10-12 hours after every washing.

6.Pressing of Fiber-After chemical treatment the important part is pressing of fiber. The fibers are made straight and then pressing of fiber is done using electric iron for converting fibers into straight and long length fibers are made straight. Then after proper pressing these fibers are bundled using rope.

7. Preparation of mould-As shown in figure-1 mold is prepared and the actual model is as shown in figure-2.This mold is prepared for hand layup process and it is performed while preparing hybrid composites specimens.Such 18 combinations are made as shown in figure-3.

8. Hand Layup Process-The specimens are prepared using hand layup proces.In this fibers are arranged in orientation and the mixture is applied before and after on it.

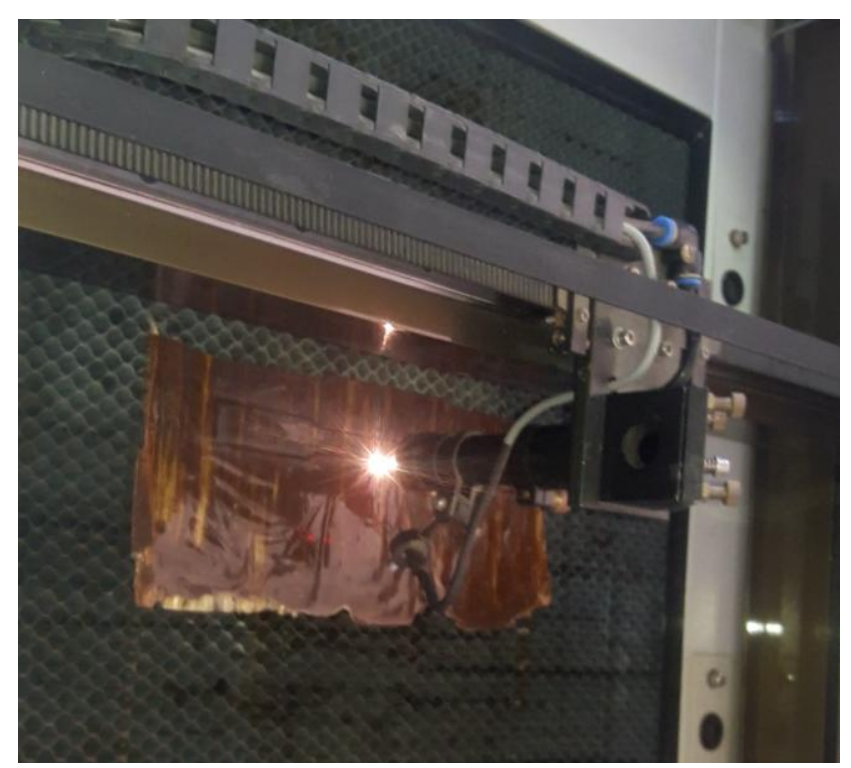

Fig.-2Laser Cutting
9. Laser Cutting-The Samples for the Tensile Test as well as for the Flexural Test are prepared using laser cutting machine for cutting with precision as shown in figure 2.The specimens cut are as follows.

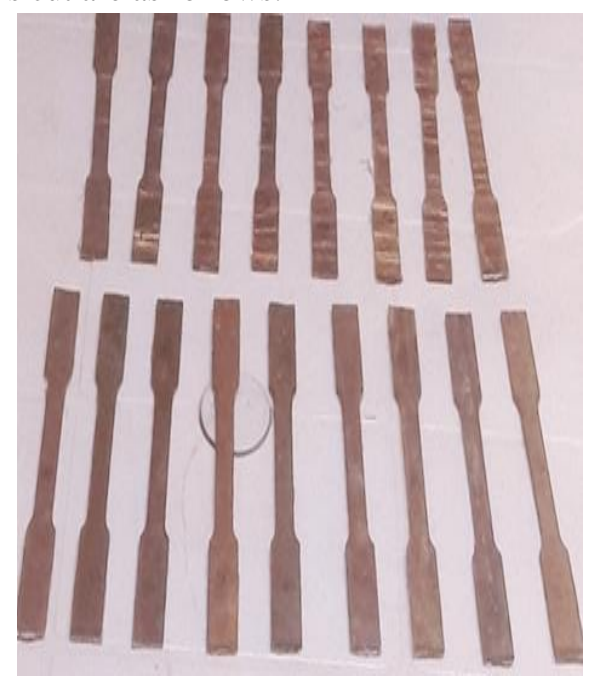

Fig.-3 Samples cut for tensile test

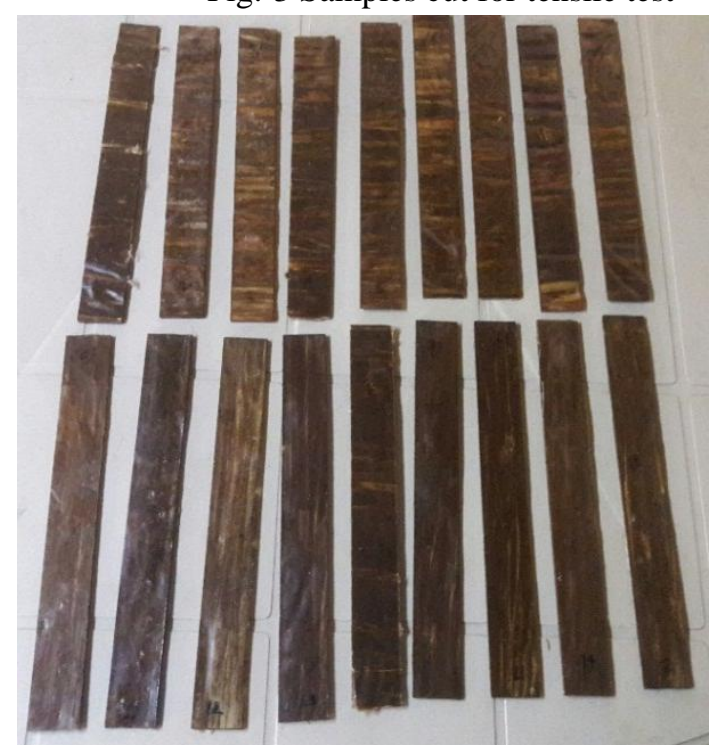

Fig.-4Samples cut for bend test

\section{RESULT AND DISCUSSION}

1. Testing and comparative analysis

After completion of cutting of specimens as per standards the samples are decided to test under different loading conditions. The tests decided are tensile, and flexural test. All samples were collectively checked for damages Possible cracks before testing were checked. The defective samples are removed and reformed from specific plates for better accuracy in testing of samples.

\section{Graphs of test for 0 and 90 degree orientations}

The following graphs are comparative graphs showing results of tensile, and bending test. From all graphs it is clear that as powder percentage increases strength increases and the less micron size showing best results of strength and in case of orientations the strength of ninety degree specimen is more than zero degree specimens with similar composition. 
LOAD N.

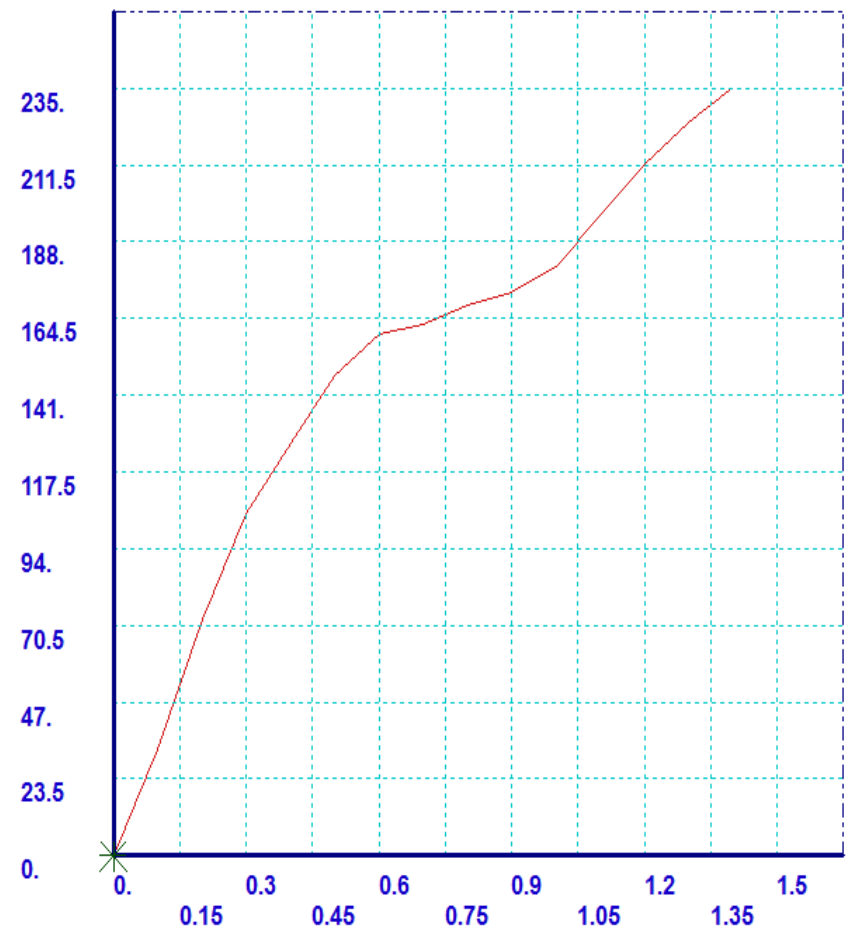

Fig.-5 Tensile Test for 0 degree orientation

LOAD N.

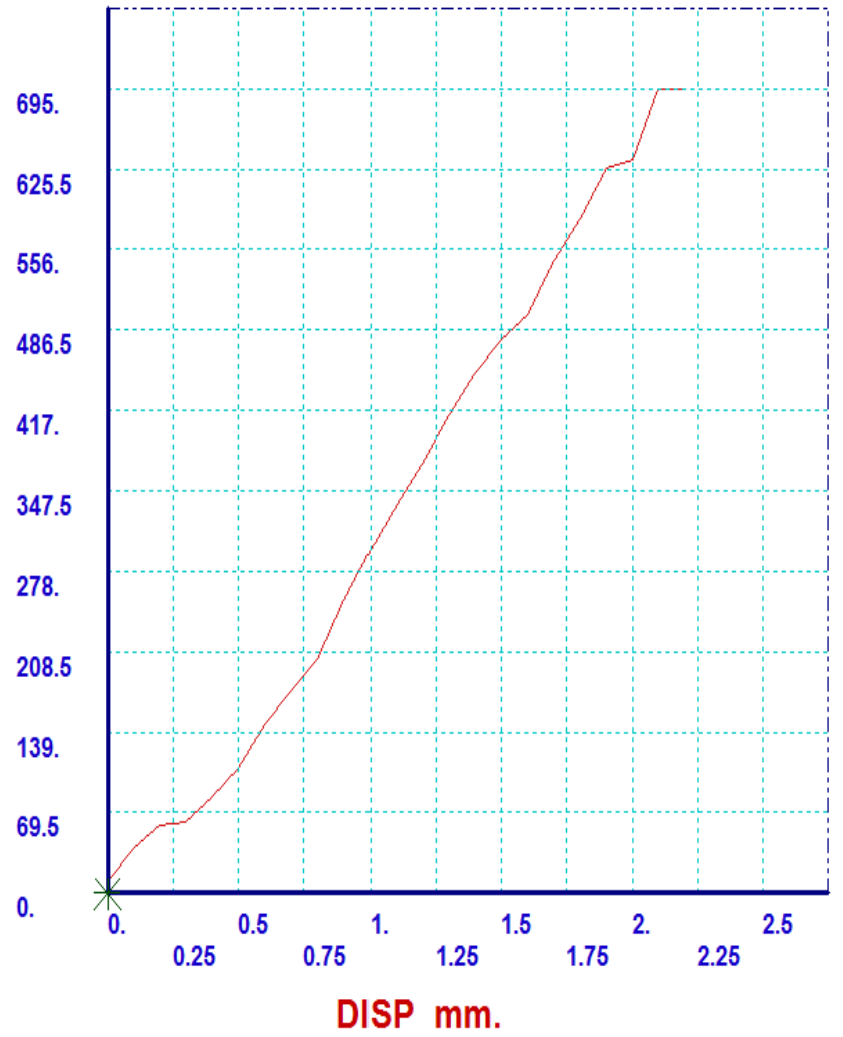

Fig.-6 Tensile Test for 90 degree orientation

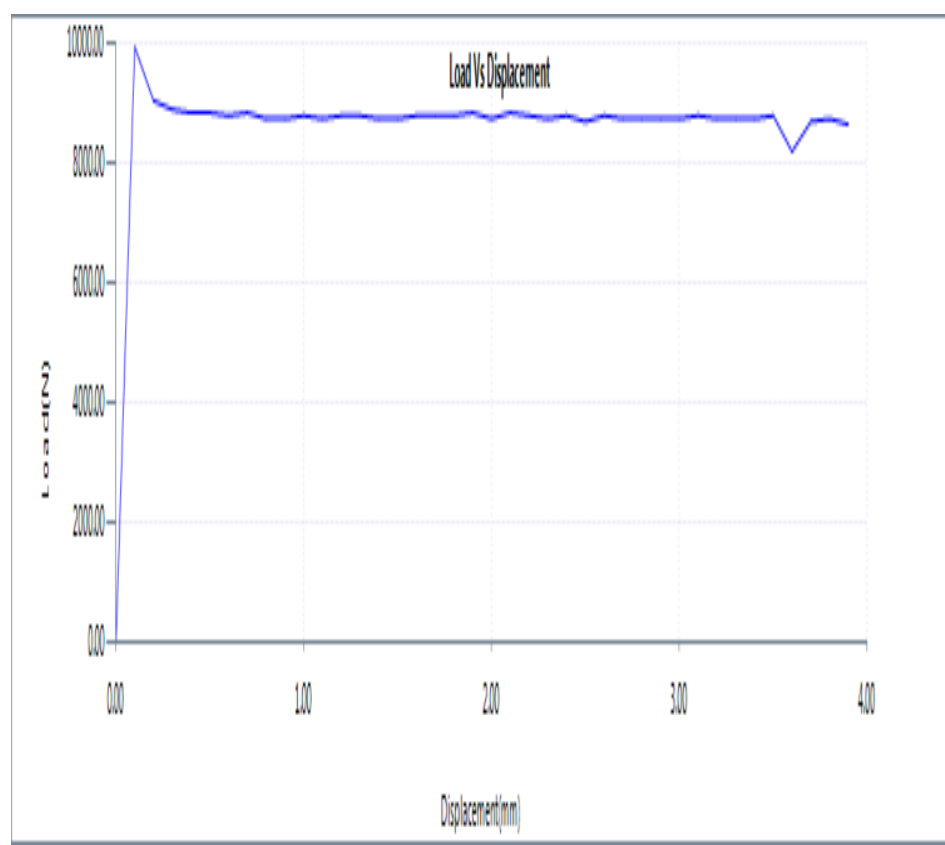

Fig.-7 Bending Test for 0 degree orientation

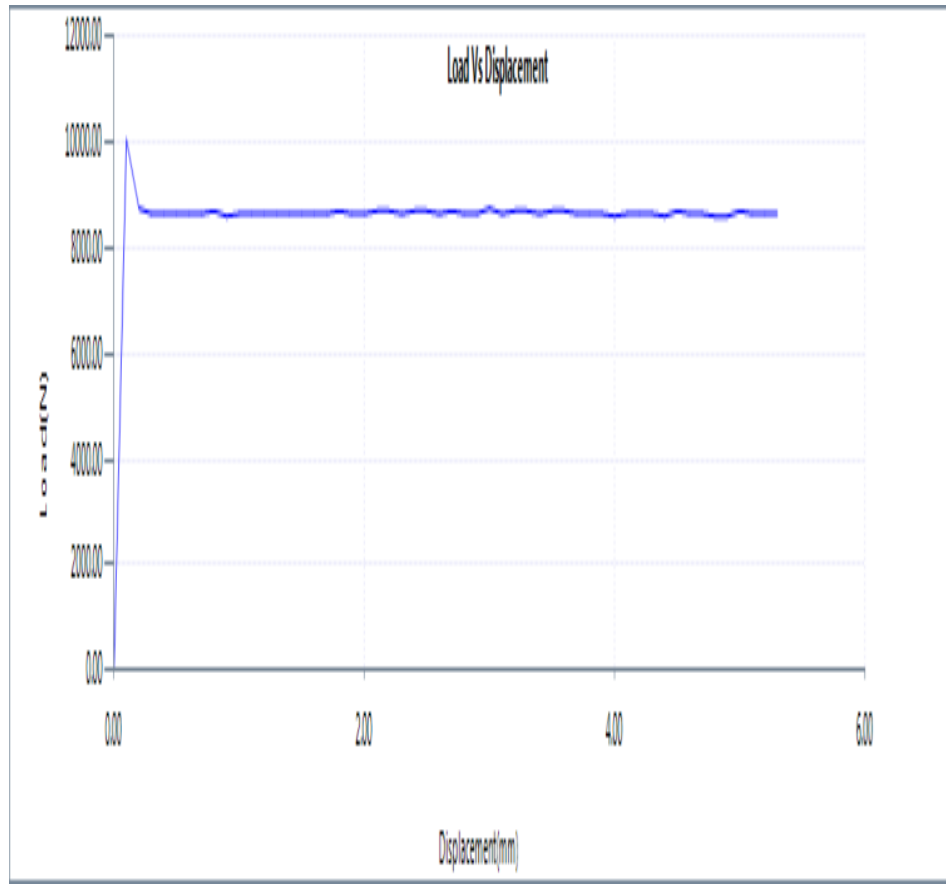

Fig.-8 Bending Test for 90 degree orientation

\section{CONCLUSION}

For $30 \%$ powder with ninety degree orientation gives best strength than others also in case of micro analysis 0-100 micron size with ninety degree and $30 \%$ powder gives the best results of strength. Also it is found that strength decreases with increase in micro size. It is found that ninety degree specimen of same composition gives more strength than zero degree specimen. It is found that material behavior is good for bend test than tensile test and also it is found that with increase in powder percentage strength increases. 


\section{ACKNOWLEDGMENT}

The authors wish to thank Dr. B. P. Ronge the principal of College of Engineering, Pandharpur, H.O.D. and mechanical staff for completion of project work.

\section{REFERENCES}

[1] Melvin Jacob, Muhammad NaseefPaleri, Riswankp , SanalDevkn, SonuShilhad, 2019, Natural Hybrid Composite, SSRG International Journal of Mechanical Engineering (SSRG-IJME) - Volume 6 Issue 6, Pages 1-2.

[2] P. Sathish, R. Kesavan, VijayaRamnath ,C. Vishal , 2015, Effect of Fiber Orientation and Stacking Sequence on Mechanical and Thermal Characteristics of Banana-Kenaf Hybrid Epoxy Composite, Springer Silicon, 2017, DOI 10.1007/s12633-015-9314-7, Pages 577-585.

[3] Flavio de Andrade Silva, Nikhilesh Chawla, and Romildo Dias Toledo Filho3, 2010, Mechanical Behavior of Natural Sisal Fibers Journal of Biobased Materials and Bioenergy Vol. 4, Pages 1-8.

[4] Badrinath R. and Senthilvelan T., 2014, Comparative investigation on mechanical properties of banana and sisal reinforced polymer based composites. Procedia materials science, Pages 2263-2272.

[5] Rahul Kumar, R. Kumar \&Bhowmik, S. 2015, Analysis of Mechanical Properties of Wood Dust Reinforced Epoxy. In Advanced Materials Research (Vol. 1119, pp. 258-262). Trans Tech Publications, Pages 258-262.

[6] Suman Devi, Ena Gupta, Neelesh Kumar Maurya June 2020,Development of a value added Amla product, IAAST Vol 11 [2], Pages 90-92.

[7] Danuta Matykiewicz,11 April 2020, Hybrid Epoxy Composites with Both Powder and Fiber Filler, A Review of Mechanical and Thermomechanical Properties, Materials 2020, 13, 1802; doi:10.3390/ma13081802 w, Pages 1-22.

[8] Min ZhiRonga,b, Ming QiuZhangb, Yuan Liub, Gui Cheng Yangb, Han Min Zengb, March 2001, The effect of fiber treatment on the mechanical properties of unidirectional sisal-reinforced epoxy composites, Composites Science and Technology 61 (10) Pages 1437-1447.

[9] Chandramohan, D. and Marimuthu, K., 2011,A review on natural fibers. International Journal of Research and Reviews in Applied Sciences, 8(2), Pages 194-206.

[10] K. V. Sreenivas Rao, N. S. Venkatesha Gupta, Akash and Sanjeevamurthy, Vol.11 No.-1,January 2016, Mechanical properties of natural fibers reinforced hybrid composites, Journal of Engineering and Applied Sciences, Pages 253-258.

[11] Fiore V., A. Valenza, Volume 85, February 2016, A new eco-friendly chemical treatment of natural fibers: Effect of sodium bicarbonate on properties of sisal fibre and its epoxy composites, Pages 150-160.

[12] Bartosz T, W cławski a, Mizi Fan a, David Hui b, July 2014 Compressive behaviour of natural fibre composite, Composites, ISSN Part B 67-2014) Pages 183-191.

[13] A. Ticoalu, T. Aravinthan\& F. Cardona, Southern Region Engineering Conference 11-12 November 2010, Toowoomba, Australia SREC2010-F1-5 1 SREC2010-F1-5 A review of current development in natural fiber composites for structural and infrastructure applications, Pages 1-5.

[14] Badrinath R. and Senthilvelan T., 2014, Comparative investigation on mechanical properties of banana and sisal reinforced polymer based composites. Procedia materials science, Pages 2263-2272.

[15] Ramesh, M. Atreya, T.S.A. Aswin, U. S. Eashwar, H. and Deepa C., 2014, Processing and mechanical property evaluation of banana fiber reinforced polymer composites. Procedia Engineering, 97, Pages $563-$ 572.

[16] NurInani Abdul Razak , Nor Azowa Ibrahim, NorhazlinZainuddin, MarwahRayung, Molecules 2014, The Influence of Chemical Surface Modification of Kenaf Fiber using Hydrogen Peroxide on the Mechanical Properties of Biodegradable Kenaf Fiber/Poly Composites, ISSN 1420-3049,Pages 2957-2968.

[17] Vijay K. Kaushik1, Anil Kumar, SusheelKalia, May 2012, Effect of Mercerization and Benzoyl Peroxide Treatment on Morphology,
Thermal Stability and Crystallinity of Sisal Fibers, International Journal of Textile Science 2012, 1(6)-Pages 101-105.

[18] Asabe, P.B., Bhosale, S. B, Wangikar, S.S., Kalebag V. G., Mahajan, O.L. and Parkhe, A.K., 2020, Manufacturing of Banana Fiber Composite Material.Aegaeum Journal, 8(4), pp. 405-411. 